\title{
EDITORIAL
}

\section{Fonoaudiologia: reabertas as discussões sobre especialidades}

\author{
Ana Claudia Miguel Ferigotti, Leila Nagib
}

O desenvolvimento técnico-científico e a evolução tecnológica têm levado as profissões em geral, e entre elas as profissões da saúde, a reflexão e discussões acerca do processo de trabalho que desenvolvem e dos conhecimentos, habilidades e atitudes para tanto necessárias. Nesse contexto, a Fonoaudiologia, profissão cuja essência e especificidade é a comunicação humana em todas as suas dimensões, repensa o seu futuro e o futuro das especialidades.

O Sistema dos Conselhos de Fonoaudiologia retomou questões relativas à atualização e/ou criação das especialidades, realizando um estudo aprofundado da fase de desenvolvimento em que se encontra a Fonoaudiologia (mercado de trabalho e atividade profissional), baseando-se nos aspectos científicos, culturais, éticos e ocupacionais destinados a propiciar o aprimoramento técnico-científico para o exercício profissional especializado. Considerando os avanços desenvolvidos em diversas esferas políticas, sociais e do conhecimento, a análise prévia sinaliza para a criação de novas especialidades no âmbito da Fonoaudiologia.

Bem sabemos que as especialidades sujeitam-se aos processos dinâmicos da Fonoaudiologia, não podendo, por isso, serem permanentes, nem imutáveis, podendo inclusive, dependendo das circunstâncias e necessidades, sofrer mudanças de nomes, fusões, criações e/ou extinções.

Se retornarmos os caminhos já percorridos para a criação das especialidades na área da Fonoaudiologia, concluímos que a discussão sobre as especialidades no início da década de 90, culminando com a publicação da primeira Resolução sobre o tema em 1996, que definiu, naquela época, quatro áreas de especialidades na Fonoaudiologia - Audiologia, Linguagem, Motricidade Oral e Voz.

A inserção social do fonoaudiólogo, a atividade profissional e a ampliação de mercado de trabalho, fizeram com que a classe profissional retomasse o debate no ano de 2001, iniciando novo processo para a atualização das resoluções pertinentes à especialização.

Nesse contexto, com o objetivo de organizar metodologicamente os trabalhos, foi utilizado o método Dacum - metodologia de descrição de ocupações e curriculos, seguindo os principios de educação baseada em competências - com a finalidade de estabelecer dinâmicas que ajudassem a definir as lacunas que exigiam a criação de novas especialidades.

Importante salientar que como produto desse estudo e por considerar importante subsidiar a classe nas discussões em diversas esferas onde a Fonoaudiologia se encontra, bem como, esclarecer os demais profissionais de outras áreas da saúde acerca das atividades desenvolvidas pelo fonoaudiólogo, o CFFa editou, em dezembro de 2002, documento denominado "Exercício Profissional do Fonoaudiólogo no Brasil - Caracterização das ações inerentes ao exercício profissional do fonoaudiólogo". Em 2007 o CFFa editou a $2^{\text {a }}$ versão do referido documento, revisada e ampliada, denominada: "Áreas de Competência do Fonoaudiólogo no Brasil”.

Entre 2002 e 2005, consultas, fóruns e pesquisas foram realizadas pelo CFFa junto aos Conselhos Regionais, à Sociedade Brasileira de Fonoaudiologia e à classe fonoaudiológica, resultando em 2006, 
na publicação de Resoluções atualizando e normatizando o reconhecimento de cinco especialidades profissionais pelo CFFa: Audiologia, Linguagem, Motricidade Orofacial, Voz e como nova área a Saúde Coletiva.

O CFFa não se deteve e tem dado continuidade ao assunto especialidade, já que o desenvolvimento da profissão está cada vez mais atrelado à progressão e à aplicação das políticas públicas no país, além da solicitação dos profissionais que clamam por inscrições de novas tendências. Desta forma, o CFFa abriu recentes discussões dentro do Sistema dos Conselhos de Fonoaudiologia, convidando Sociedade Brasileira de Fonoaudiologia, Academia Brasileira de Audiologia, Instituto Brasileiro de Fluência, Associação Brasileira de Gagueira, Instituições de Ensino Superior, especialistas nas áreas e fonoaudiólogos, por meio de seus Conselhos Regionais, para debates e opiniões aparelhados com o histórico das especialidades, com o levantamento de dados sobre os concursos realizados, com o estudo das especialidades, com o número de fonoaudiólogos especialistas por região, com o levantamento das especialidades em profissões da saúde. Para a discussão dos novos rumos, visando a compreensão e o registro cada vez maior da profissão, da ciência Fonoaudiologia, o CFFa tem promovido audiências com os órgãos afins. Realizou em 28 e 29 de agosto de 2009 reunião Interconselhos sobre as especialidades da Fonoaudiologia e com base na Classificação Brasileira de Ocupações (CBO), como documento normatizador do reconhecimento, da nomeação e da codificação dos títulos e conteúdos das ocupações do mercado de trabalho brasileiro, verificou-se que há uma tendência para a criação de quatro novas especialidades: Disfagia, Fluência, Fonoaudiologia Escolar/Educacional e Fonoaudiologia do Trabalho. Os critérios para o encaminhamento da criação destas áreas de especialidades na Fonoaudiologia estão sendo, entre outros, os seguintes:

- Possuir complexidade e acúmulo de conhecimentos que transcendem o aprendizado do curso de graduação em Fonoaudiologia e que possuam uma área raiz, em um setor específico;

- Possuir relevância epidemiológica e demanda social definida;

- Possuir programa de treinamento teórico/prático que demande um período mínimo de 360 horas, conduzido por orientador qualificado da área específica;

- Reunir um conjunto de métodos e técnicas, que propiciem aumento da resolutividade diagnóstica e/ou terapêutica;

- Reunir conhecimentos que definam um núcleo de atuação própria que não possa ser englobado por especialidades já existentes.

Além disso, as cinco áreas de especialidades já reconhecidas anteriormente pelo CFFa, a saber, Audiologia, Linguagem, Motricidade Orofacial, Saúde Coletiva e Voz foram analisadas e novas nomenclaturas estão sendo propostas com vistas a adequação às demandas nacionais e internacionais.

A partir deste documento o $\mathrm{CFFa}$, com o apoio da $\mathrm{SBFa}$, suscitará trabalhos e reuniões no $17^{\circ}$ Congresso Brasileiro de Fonoaudiologia, intitulado "Fonoaudiologia: Conhecimento e Integração", para a finalização das discussões na seleção das grandes áreas de atuação do fonoaudiólogo. Dentre as ações, a consulta pública acerca do tema especialidades será disponibilizada antes e durante o Congresso, para que toda a comunidade fonoaudiológica possa se manifestar em relação às propostas de novas áreas de especialidades, nomenclaturas, competências, área do conhecimento e função, bem como, se manifestar em relação a outras especialidades e áreas de atuação fonoaudiológicas que entendem poder vir a ser reconhecidas. 
Nada mais propício e democrático, desde o local, a ocasião e a temática do Congresso de 2009. Este hábito, praticado por gestões anteriores do sistema Conselhos de Fonoaudiologia, será continuado por esta atual. Mais que o binômio oferta e procura no mercado de trabalho competitivo que vivemos e à frente da reciclagem profissional e do desenvolvimento dos domínios da ciência, o CFFa ouve o fonoaudiólogo e age eticamente diante da profissão/ciência Fonoaudiologia, para a qualificação integrada de conhecimentos técnicos, sociais, econômicos e culturais e no estabelecimento de sólidas e novas parcerias na busca da promoção da saúde. Até o $17^{\circ}$ Congresso Brasileiro de Fonoaudiologia. Queremos ouvi-lo!

Ana Claudia Miguel Ferigotti - Presidente da CATECE Leila Nagib - Presidente do CFFa 